NASA Technical Memorandum 100179

\title{
Fiber Composite Structural Durability and Damage Tolerance: Simplified Predictive Methods
}

Christos C. Chamis and Carol A. Ginty

Lewis Research Center

Cleveland, Ohio

Prepared for the

Second Symposium on Composite Materials: Fatigue and Fracture sponsored by the American Society for Testing and Materials Cincinnati, Ohio, April 26-May 1, 1987

\section{NMSn}


FIBER COMPOSITE STRUCTURAL DURABILITY AND DAMAGE TOLERANCE:

\author{
SIMPLIFIED PREDICTIVE METHODS
}

\author{
Christos C. Chamis and Carol A. Ginty \\ National Aeronautics and Space Administration \\ Lewis Research Center \\ Cleveland, Ohio 44135
}

\begin{abstract}
SUMMARY
Simplified predictive methods and models ("theory") to evaluate fiber/ polymer-matrix composite material for determining structural durability and damage tolerance are presented and described. This "theory" includes equations for (1) fatigue and fracture of composites without and with defects, (2) impact resistance and residual strength after impact, (3) thermal fatigue, and (4) combined stress fatigue. Several examples are included to illustrate applications of the "theory" and to identify significant parameters and sensitivities. Comparisons with limited experimental data are made.
\end{abstract}

\title{
INTRODUCTION
}

A major and continuing concern in the fiber-composites community has been the accurate prediction (even a good approximation) of the structural durability and damage tolerance of fiber composite structures in service environments. Hygrothermomechanical service environments are of major concern; that is, temperature, moisture, mechanical loads (static, cyclic, and impact), and various combinations of these environments. In response to this concern, a recent research effort at the NASA Lewis Research Center was directed towards the development of the methodology required to predict the life and/or durability and damage tolerance of composite structural components in aerospace propulsion environments. This paper describes that part of the research effort which is to develop simplified and approximate predictive methods and models for determining the structural durability and damage tolerance of fiber composite structural components subjected to hygrothermomechanical aerospace environments.

These simplified predictive methods and models ("theory") have evolved over the years by investigating a broad range of composite behavior. These models are of generic, isoparametric form for all contributing variables (moisture, thermal, stress, and fatigue cycles). The models are applicable to structural components with and without defects. The defects can be those resulting from fabrication, induced damage (impact), or inadvertent damage. The models are based on composite micromechanics and ply-stress influence coefficients, thereby rendering them generic and applicable to all types of fiber/polymer-matrix composites including intra- and interply hybrids.

The mathematical form of the models and the significance of the terms in the equations are described in detail. Use of the models for various applications is illustrated by select examples. These examples include the following (in part):

(1) Fatigue and fracture of smooth and notched laminates

(2) Impact resistance 
(3) Residual strength after impact

(4) Residual stresses

(5) Fatigue and fracture after thermal cycling

(6) Crack development after thermal cycling

(7) Thermal and mechanical load cycles to microcrack formation

Predicted results are compared with available experimental data and discussed with respect to their significance and application to design.

\section{FUNDAMENTAL CONSIDERATIONS}

Several fundamental aspects underlie the development of the simplified predictive methods included in this paper. These aspects and respective justifications are as follows:

1. Holes, slits, and impact damage (defects) induce similar strength degradation in fiber-composite laminates where the characteristic dimensions of these defects are negligible compared to the planform dimensions of the laminate. If this is not the case, the effects of the defects must be evaluated using appropriate structural analyses. Experimental data for holes and slits are shown in figure 1 (ref. 1), figure 2 (ref. 2), and in table I (ref. 2). It is worth noting in table I that the failure modes are almost identical for the smooth (unnotched) and defected (notched) laminates.

2. Fatigue degrades all ply strengths at approximately the same rate. Experimental data for longitudinal compression, transverse compression, and interlaminar shear $[ \pm 45]_{S}$ fatigue is shown in figure 3 (ref. 3 ). Additional relevant data are included in reference 4 .

3. All types of fatigue degrade laminate strength linearly on a semilog plot including: (a) mechanical (tension, compression, shear, and bending); (b) thermal (elevated and cryogenic temperature); (c) hygral (moisture); and (d) combinations (mechanical, thermal, hygral, and reverse-tension compression). Experimental data for compression fatigue is shown in figure 4 (ref. 1).

4. Laminates generally exhibit linear behavior to initial damage under uniaxial or combined loading including hygrothermal effects.

5. All ply stresses (mechanical, thermal, and hygral) are predictable by using linear laminate theory.

6. Stress concentration factors for circular holes are available. They can be obtained from the literature (ref. 5) or can be predicted by using finite element analysis.

\section{SIMULATION OF DEFECTS AND STRESS CONCENTRATIONS}

The simulation of defects (holes, slits, and impact damage) for approximate analysis is depicted schematically in figure 5 and is consistent with the justifications previously mentioned. It can be seen from the figure that impact damage and slanted slits are also simulated with circular holes. The difference between the horizontal slit and the slanted slit is the stress 
state in the "removed" vicinity of the slit. This state is uniaxial for the horizontal slit but is combined for the slanted slit.

The stress concentration factor at any point around the perimeter of the circular hole, for combined stresses, is obtained by superposing the respective stress concentration factors for the individual stress states. This is depicted schematically in figure 6 where equations for stress concentration factors are given under the respective schematic (ref. 5). The equations are explicit and relatively simple. (The notation is readily deduced from the schematics and is also summarized in appendix $A$.) These equations reduce to the well known stress concentration factors for isotropic material as follows:

(1) $K_{T}(x)=3\left(\theta=90^{\circ}\right.$ for $\sigma_{C x x}$ or $\theta=0^{\circ}$ for $\left.\sigma_{C y y}\right)$

(2) $K_{T}(y)=-1\left(\theta=0^{\circ}\right.$ for $\sigma_{C x x}$ or $\theta=90^{\circ}$ for $\left.\sigma_{C y y}\right)$

(3) $K_{T}(x y)=-4\left(\theta=45^{\circ}\right.$ and $225^{\circ}$ for $\left.\sigma_{C x y}\right), K_{T}(x y)=4\left(\sigma=135^{\circ}\right.$ and $315^{\circ}$ for $\left.\sigma_{C x y}\right), K_{T}=0\left(\theta=0^{\circ}, 90^{\circ}, 180^{\circ}, 270^{\circ}\right.$ and $360^{\circ}$ for $\left.\sigma_{\text {Cxy }}\right)$

In order to use the stress concentration equations in figure 6 , the following factors must be known: (1) the laminate elastic constants about the structural axes and (2) the tangential modulus $E_{c \theta \theta}$ at the point where the stress concentration factor is being calculated. These are easily determined by using laminate theory and the well known transformation equations (refs. 6 and 7). For general laminates under combined stress the position $\theta$ at which $\sigma_{c} \theta \theta$ is maximum is generally unknown. One way to determine the position $\theta$ is to calculate the stress concentation factors $K_{T}$ at regular small angle intervals (about $5^{\circ}$ ) and then determine the maximum $\sigma_{\mathrm{C} \theta \theta}$ from

$$
\begin{gathered}
\sigma_{C \theta \theta}=\operatorname{Max}\left(K_{T}(x) \sigma_{C x x}+K_{T}(y) \sigma_{y y}+K_{T}(x y) \sigma_{C x y}\right) \\
\left(0 \leq \theta \leq 180 \text { at } \theta=5^{\circ} \text { intervals }\right)
\end{gathered}
$$

where $\sigma_{C x x}$, $\sigma_{c y y}$, and $\sigma_{c x y}$ are the far-field stresses and are generally known from structural analysis.

The ply-stress concentrations at that $\theta$ are then calculated by using laminate theory or ply-stress influence coefficients (refs. 7 and 8). In order to use the ply-stress influence coefficients, it is usually convenient to transform the local stress $\sigma_{c \theta \theta}$ to an equivalent structural axes-stress state obtained from the following equations:

$$
\left.\begin{array}{l}
\sigma_{C x x}=\sigma_{C \theta \theta} \sin ^{2} \theta \\
\sigma_{C y y}=\sigma_{C \theta \theta} \cos ^{2} \theta \\
\sigma_{c x y}=\frac{-1}{2} \sigma_{C \theta \theta} \sin 2 \theta
\end{array}\right\}
$$

The ply stresses can now be determined from the following ply-stress influence coefficient matrix equations: 


$$
\left\{\begin{array}{c}
\sigma_{\ell 11} \\
\sigma_{\ell 22} \\
\sigma_{\ell 12}
\end{array}\right\}=\left[\begin{array}{lll}
\mathscr{I}_{L / X} & \mathscr{I}_{L / Y} & \mathscr{I}_{L / S} \\
\mathscr{I}_{T / X} & \mathscr{I}_{T / Y} & \mathscr{I}_{T / S} \\
\mathscr{I}_{S / X} & \mathscr{I}_{S / Y} & \mathscr{I}_{S / S}
\end{array}\right]\left\{\begin{array}{c}
\sigma_{c x x} \\
\sigma_{c y y} \\
\sigma_{c x y}
\end{array}\right\}
$$

This equation is easily used when the ply-stress influence coefficients are available (ref. 8) as summarized in appendix $B$. If not readily available, they can be determined from laminate theory, in general.

In summary, the step-by-step procedure for determining the ply-stress concentrations, to be used for durability and damage tolerance assessment of composites by using simplified methods, is as follows:

(1) Replace the defect with an equivalent hole in an infinite medium.

(2) Determine the elastic properties of the laminate.

(3) Generate tables for the stress concentration factors at regular angle intervals (about $5^{\circ}$ ) by using equations in figure 6 and the tangential modulus equation which can be found in appendix $B$.

(4) Determine the far-field stress state due to the loading conditions. Note that this stress state must be transformed for the slanted slit case as noted in figure 5 .

(5) Determine the maximum value for $\sigma_{C \theta \theta}$ from equation (1).

(6) Determine the laminate-stress concentrations due to $\sigma_{c \theta \theta}$ from equation (2).

(7) Determine the corresponding ply-stress concentrations from equation ( 3 ).

\section{FATIGUE AND FRACTURE FOR MECHANICAL LOAD ONLY}

Durability and damage tolerance is generally assessed by determining the stress that the composite can sustain (1) under repeated loading (fatigue), (2) after damage, and ( 3 ) combinations thereof. The simplified methods (equations) for determining the fatigue stress of composites without and with defects with constant stress amplitude are summarized in figure 7 for mechanical loads only. These simple methods predict the fatigue and fracture in the first ply in its weakest (first-to-fracture) mode which may be thought of as either defect initiation or defect growth initiation. The hygrothermal effects are accounted for in the equations as well as the stress concentration effects. In order to use these equations to determine the ply-fatigue uniaxial stress Secyc at initial defect growth, all the other variables in the equations must be known. For example, the service environment temperature $T$ and the number of cycles $\mathrm{N}$ are known from the design requirements. The glass transition temperature in the presence of moisture $T_{G W}$ can be estimated from the equation (ref. 8 ) in appendix $B$. The cyclic stress degradation coefficient $B$ is usually determined from experimental data (ref. 3 ). 
Comparisons of the predicted results from the equation for composites without defects are shown in figure 3 for graphite and epoxy and in figure 8 (ref. 9) for glass and polyester. In both of these figures the agreement is considered good since it appears to provide a lower bound.

Comparisons for composites with defects under reverse fatigue are shown in figure 9. The two predicted curves in this figure show the difference between the static fracture stresses for tension and compression. As can be seen the experimental data are approximately between the two predicted curves.

\section{IMPACT RESISTANCE}

The simplified methods (equations) for predicting the composite damage due to impact are outlined in figure 10. The notation used in the equations is self-evident. The quantified damage is that due to internal delamination which is generally not visually detectable. The energy balance is determined by assuming the following: (1) the impacting projectile does not impart any velocity to the target, (2) the projectile does not absorb any energy, and (3) that delamination is "generally" initiated simultaneously in several interply locations through the thickness. This third assumption is based primarily on observations of dissected, impacted laminates which generally show several interply delaminations but no surface damage (ref. 1).

The important composite parameters in these equations are (1) the laminate thickness $t_{C}$ and (2) the composite interlaminar shear strength $S_{\ell 13}$. The impacting velocity or height-drop to induce delamination will increase linearly with composite thickness and/or with composite interlaminar shear strength. For example, assume (1) that the typical interlaminar shear strength for graphite-fiber/epoxy composites is $12 \mathrm{ksi}$, (2) the laminate is $0.1-i n$. thick, and (3) a 1-in.-diameter steel ball is the projectile, then the impacting velocity to initiate delamination is

$$
\begin{aligned}
& V=\left[0.75\left(386.4 \frac{\mathrm{in.}}{\mathrm{sec}^{2}} \frac{\mathrm{in} .}{0.3 \mathrm{ib}}\right)\left(\frac{0.1 \mathrm{in.}}{1.0 \mathrm{in.}}\right) 12000 \frac{\mathrm{lb}}{\mathrm{in.}^{2}}\right]^{1 / 2} \\
& V=1077 \mathrm{in.} / \mathrm{sec} \approx 90 \mathrm{ft} / \mathrm{sec}
\end{aligned}
$$

which is reasonable and consistent with suggested literature values (ref. 10).

In another example, the height-drop equivalent for delamination initiation of a 25-1b tool box is estimated by using the same laminate. By employing the last equation in figure 10 , assuming that the impactor is $1-i n$. in diameter, and the equivalent density is about $50 \mathrm{lb} / \mathrm{in}^{3}{ }^{3}$, the height-drop equivalent $H$ is

$$
\begin{aligned}
& H=\left[1.5(0.1 \mathrm{in.} / 1 \mathrm{in} .)\left(12000 \mathrm{lb} / \mathrm{in} .{ }^{2}\right) / 50 \mathrm{lb} / \mathrm{in}^{3}\right] \\
& H=36 \mathrm{in} .=3.0 \mathrm{ft}
\end{aligned}
$$

which is also reasonable based upon literature values (ref. 11). 
The two previous numerical examples demonstrate the applications of equations in figure 10 for estimating impact loads to be used, in turn, for the sizing of laminates during preliminary design phases. It is understood that these laminate designs must be validated with more sophisticated analyses (for example, finite element) and verified with strategically selected experiments.

\section{THERMAL FATIGUE AND THERMAL CYCLES TO INITIAL CRACKING}

The simplified method, criteria, concept, and equation to predict the thermal cycles to initial transply cracking (referred to as microcracking in the literature (ref. 12)) are summarized in figure 11 . It is important to note in this figure that the cyclic temperature amplitude $\Delta T$ is measured from the cure temperature which is different than the glass transition temperature (dry or wet). The predictive model (equation) for the number of thermal cycles $\mathrm{N}_{T}$ is shown at the bottom of figure 11. In order to use this equation, the various temperatures $T_{G W}, T_{G D}, T$, and $T_{0}$, the cyclic temperature (elevated, room, cryogenic) amplitude $\Delta T$, the room temperature ply-transverse strength $S_{\ell 220}$, the ply-transverse stress $\sigma_{\ell 22 c y c}$, and the thermal fatigue degradation coefficient $B$ must be known.

The step-by-step procedure for using this equation is as follows:

(1) Obtain $T_{G D}$ from the material supplier.

(2) Determine TGW from the equation in Appendix $B$ for the mission-specified moisture.

(3) Obtain $T$ from the mission-specified conditions. This is usually the maximum and minimum cyclic temperature.

(4) Room temperature in general is the reference temperature, To

(5) Obtain $S_{l 220}$ from the material supplier or by using micromechanics equations (ref. 13).

(6) Calculate the cyclic ply-transverse stress $\sigma_{\ell 22 c y c}$ by using laminate theory at the corresponding $\Delta T$.

(7) Select an appropriate value for the thermal fatigue degradation coefficient $B$. Values for this coefficient are not currently available in the literature to the authors' knowledge. However. some guidelines for selecting estimates are described in reference 3 .

To demonstrate, this procedure was used to predict the number of thermal cycles to transply crack initiation for two laminate configurations with three different cyclic temperatures $\left(\Delta T=-100,-280\right.$, and $\left.-600^{\circ} \mathrm{F}\right)$. The results are summarized in table II. As expected, the laminate configuration and the cyclic temperature influence the number of thermal cycles to transply crack initiation. One very interesting and surprising result is the high sensitivity of the thermal cycles to relatively small changes in the magnitude of the thermal ply-transverse stress at cryogenic temperatures. As can be seen in the table, an increase of 2 percent in cryogenic stress magnitude causes a decrease of 44 percent in thermal cycles.

Factors which contribute to the transverse ply stress will also contribute significantly to the number of thermal cycles to initial transply cracking. The most prominent of these factors and most difficult to quantify accurately include (1) temperature profile through the laminate thickness, (2) thermal cyclic degradation coefficients $B$, and ( 3 ) in situ ply-transverse strength. 
The sensitivity of the temperature profile through the laminate thickness on the number of thermal cycles to initial transply cracking is shown in table III. As can be seen it is very significant. It also illustrates, in part, the difficulty that would be encountered in pinpointing this number by measurement. The results in this table also show that the smallest number of cycles occurs for the ply with the greatest temperature difference. These results are consistent with the findings reported in references 12 and 14 .

The sensitivity of the number of thermal cycles to (1) thermal cyclic degradation coefficient $B$ and (2) in situ ply-transverse strength $S_{l o}$ are shown in figure 12(a) for elevated temperature cycling and in figure 12(b) for cryogenic temperature cycling. The following characteristics are observed from these two figures:

(1) The thermal cycles $N_{T}$ are very sensitive to $B$ for values around 0.1 and also to $S_{l o}$.

(2) The sensitivity is more manifest in cryogenic temperature cycling than in elevated temperature cycling.

(3) The sensitivity diminishes progressively as $B$ increases beyond 0.3 for both temperatures except for the 50 percent $S_{l O}$ curve at cryogenic temperatures.

The important conclusion from this discussion is that the predictive model in figure 11 provides a simple and effective means to estimate the thermal cycles to initial transply cracking and its sensitivity to various participating parameters.

\section{COMBINED HYGROTHERMOMECHANICAL CYCLIC LOADING}

The predictive equation for combined cyclic loading is shown in figure 13 . The combined loading includes (1) steady state, (2) mechanical load cycling, (3) thermal cycling, and (4) hygral (moisture) cycling. The notation used in the figure is appropriately defined. Note that the equation, as shown, applies only to one uniaxial ply stress and for constant amplitude of each of the cyclic loads.

The equation is general, however, and can be applied to a variety of conditions; for example, (1) variable cyclic amplitude can be handled by applying the equation to each amplitude and then summing the corresponding terms and (2) combined stress states can be handled by using available combined stress failure criteria (ref. 7). In either case, care should be exercised in using the respective cyclic stress degradation coefficients for the various ply stresses. The recommended (default) value from reference 3 is 0.1 for this coefficient for all types of stresses when no other values are available.

The predictive equation in figure 13 was used to estimate the number of cycles for various loading conditions for three different laminates:

(1) $[ \pm 45 / 0 / 90]_{5}$ - quasi-isotropic

(2) $\left[90_{2} / \pm 10\right]_{5}$ - pressure vessel

(3) $\left[ \pm 30 / 0_{3}\right]_{S}$ - engine blade 
The results obtained are summarized in table IV. It can be seen that (1) mechanical load with residual stress is the most critical, (2) moisture cycling, only, is insignificant for 1 percent moisture by weight and can be neglected, and (3) blade laminate configurations are not likely to exhibit transply cracks under any cyclic loading conditions within practical ranges. The significant point is that the combined cyclic stress degradation effects can be evaluated for a variety of conditions by using the predictive models described in figure 13.

\section{SUMMARY OF RESULTS}

The results of an investigation to present and describe simplified predictive methods and models ("theory") for composite structural durability and damage tolerance are summarized in general as follows:

1. The theory consists of simplified closed form equations which are used to assess composite material property, structural durability, and/or damage tolerance.

2. The theory accounts for fatigue and fracture for the most commonly occurring inadvertent defects in composites.

3. The theory is limited to predicting cycles to initial damage or initial defect extension.

4. The theory is based on integrated composite mechanics, accounts for hygrothermal effects, and is applicable to combined hygrothermomechanical cyclic loading.

5. The theory is suitable for preliminary design.

6. The theory is expedient for parametric studies (composite systems). laminate configurations, temperatures and/or moistures, and combined loading conditions.

7. The theory predicts results which appear to be reasonable for assumed representative conditions and for the limited data available. However, it should be used judiciously since additional verification is needed.

More specific findings are summarized as follows:

1. Fatigue cycles to initial cracking depend on (a) composite material, (b) laminate configuration, and (c) type of cycle loading.

2. Thermal cyclic transply crack initiation and location depend on (a) temperature gradient through the thickness, (b) environmental effects on all properties, especially on transverse strength, and (c) fatigue degradation rate of transverse strength.

3. Composite impact resistance depends on (a) laminate thickness and (b) interlaminar strength. Subsequent residual strength depends on the respective stress concentration factor. 
4. Cyclic cryogenic temperatures significantly degrade the laminate fatigue resistance more so than elevated temperatures.

5. Moisture cycling (up to 1 percent by weight) has generally negligible degradation effects on composite fatigue resistance.

6. Thermal fatigue cycles are very sensitive to low values (less than about 0.2 ) of the fatigue degradation coefficient. 


\section{APPENDIX A - SYMBOLS}

The symbols in this list are found in the schematics and equations throughout the paper and are summarized here for convenience.

B thermal fatigue degradation coefficient

E elastic modulus. as defined by subscripts

G shear modulus

g gravity acceleration

$\mathscr{I}$ ply-stress influence coefficient as defined by subscripts

$\mathrm{K}_{\mathrm{T}} \quad$ stress concentration factor

M moisture

$N$ number of cycles

$R$ ratio of cyclic stress, $\min / \max$

S strength as defined by subscripts

T temperature

To reference temperature

$T_{G D}$ dry glass transition temperature

$T_{G W}$ wet glass transition temperature

$x, y, z$ global (structural axes) coordinates

$1,2,3$ ply-material axes coordinates

$\Delta \quad$ change

$\theta \quad$ ply angle orientation

$\checkmark \quad$ Poisson's ratio as defined by subscripts

$\rho$ density as defined by subscripts

$\sigma \quad$ stress as defined by subscripts

\section{Subscripts}

C compression

c composite property

$L, T \quad$ longitudinal, transverse

\& ply property 
5 shear

s symmetric when following a laminate designation

$T$ tension

$x, y, z$ respective coordinate direction properties

$1,2,3$ respective ply-material axis properties 


\section{APPENDIX B - SUMMARY OF USEFUL EQUATIONS}

The equations summarized in this appendix are required to perform the calculations of the simplified predictive methods. (See appendix A for the notation).

Ply-stress influence coefficients are as follows:

(1) For $\sigma_{c x x} \neq 0\left(\sigma_{c y y}=\sigma_{c x y}=0\right)$,

$$
\begin{aligned}
& \mathscr{I} L / X=\frac{\sigma_{\ell 11}}{\sigma_{c X X}}=\frac{E_{\ell 11}}{E_{C X X}}\left(\cos ^{2} \theta-\nu_{c x y} \sin ^{2} \theta\right) \\
& \mathscr{I} T / X=\frac{\sigma_{\ell 22}}{\sigma_{C X X}}=\frac{E_{\ell 22}}{E_{c x x}}\left[\left(\nu_{\ell 12}-\nu_{c x y}\right) \cos ^{2} \theta+\left(1-\nu_{c x y} \nu_{\ell 12}\right) \sin ^{2} \theta\right] \\
& \mathscr{I} \cdot S / X=\frac{\sigma_{\ell 12}}{\sigma_{C X X}}=\frac{-G_{\ell 12}}{E_{C X X}}\left(1+\nu_{c x y}\right) \sin 2 \theta
\end{aligned}
$$

(2) For $\sigma_{c y y} \neq 0\left(\sigma_{c x x}=\sigma_{c x y}=0\right)$,

$$
\begin{aligned}
& \mathscr{I} L / Y=\frac{\sigma_{\ell 11}}{\sigma_{c y y}}=\frac{E_{l 11}}{E_{c y y}}\left(\sin ^{2} \theta-\nu_{c x y} \cos ^{2} \theta\right) \\
& \mathscr{I} T / Y=\frac{\sigma_{\ell 22}}{\sigma_{c y y}}=\frac{E_{\ell 22}}{E_{c y y}}\left[\left(1-\nu_{c x y} \nu_{\ell 12}\right) \cos ^{2} \theta+\left(\nu_{\ell 12}-\nu_{c x y}\right) \sin ^{2} \theta\right] \\
& \mathscr{I} S / Y=\frac{\sigma_{\ell 22}}{\sigma_{c y y}}=\frac{E_{l 22}}{E_{c y y}}\left(1+\nu_{c x y}\right) \sin 2 \theta
\end{aligned}
$$

(3) For $\sigma_{c x y} \neq 0\left(\sigma_{c x x}=\sigma_{c y y}=0\right)$,

$$
\begin{aligned}
& \mathscr{I} \mathrm{L} / \mathrm{S}=\frac{\sigma_{\ell 11}}{\sigma_{C x y}}=\frac{E_{\ell 11}}{2 G_{C x y}}\left(1-\nu_{\ell 21}\right) \sin 2 \theta \\
& \mathscr{I} \mathrm{T} / \mathrm{S}=\frac{\sigma_{\ell 22}}{\sigma_{C x y}}=\frac{-E_{\ell 22}}{G_{C x y}}\left(1-\nu_{\ell 21}\right) \sin 2 \theta \\
& \mathscr{I} \text { S/S }=\frac{\sigma_{\ell 12}}{\sigma_{C x y}}=\frac{G_{\ell 12}}{G_{C x y}} \cos 2 \theta
\end{aligned}
$$


The tangential modulus is

$$
\frac{1}{E_{c \theta \theta}}=\frac{\sin ^{4} \theta}{E_{c x x}}+\frac{\cos ^{4} \theta}{E_{c y y}}+\frac{1}{4}\left[\frac{1}{G_{c x y}}-\frac{2 v_{c x y}}{E_{c x x}}\right] \sin ^{2} 2 \theta
$$

The glass transition temperature for wet composite is

$$
T_{G W}=(0.005 M-0.1 M+1) T_{G D}
$$




\section{REFERENCES}

1. Porter, T.R., "Compression and Compression Fatigue Testing of Composite Laminates," NASA CR-168023, National Aeronautics and Space Administration, Washington, D.C., 1982.

2. Irvine, T.B., and Ginty, C.A., Journal of Composite Materials, Vol. 20, No. 3, Mar. 1986, pp. 166-184. (NASA TM-83701).

3. Chamis, C.C., and Sinclair, J.H., in Composite Materials: Testing and Design, I.M. Daniel, Ed., ASTM-STP-787, ASTM, Philadelphia, 19B2, pp. 498-512.

4. Grimes, G.C., in Test Methods and Design Allowables for Fibrous Composites, C.C. Chamis, Ed., ASTM STP-734, ASTM, Philadelphia, 1981, pp. 281-340.

5. Lekhnitskii, S.G., Anisotropic Places, Gordon and Breach, New York, 1968.

6. Agarwa1, B.D., and Broutman, L.J., Analys is and Performance of Fiber Composites, John Wiley and Sons, New York, 1980.

7 Murthy, P.L.N., and Chamis, C.C., "Integrated Composite Analyzer (ICAN) Users and Progammers Manual," NASA TP-2515, National Aeronautics and Space Administration, Washington, D.C., 1986.

8. Chamis, C.C., "Prediction of Fiber Composite Mechanical Behavior Made Simple," NASA TM-81404, National Aeronautics and Space Administration, Washington, D.C., 1980.

9. Lark, R.F., and Chamis, C.C., "Hygrothermomechanical Evaluation of Transverse Filament Type Epoxy/Polyester Fiberglass Composites," NASA TM-83044, National Aeronautics and Space Administration, Washington, D.C., 1983.

10. Liu, D., Malvern, L.E., and Sun, C.T., in Proceedings of the 1986 SEM Spring Lonference on Experimental Mechanics, Society for Experimental Mechanics, Bethe I, CT, 19B6, pp. 863-868.

11. Sollars, T.A., in Proceedings of the 28th AIAA/ASME/ASCE/AHS Structures, Structural Dynamics and Materials Conference, Part 1, AIAA, New York, 1987, pp. 362-375.

12. Wilson, D., Wells, J.K., Hay. J.N., Lind, D., and Owens, G.A., SAMPE Journal, Vol. 23, No. 3, May-June 1987, pp. 35-4l.

13. Chamis, C.C., "Simplified Composite Micromechanics Equations for Strength, Fracture Toughness, and Environmental Effects," NASA TM-83696, National Aeronautics and Space Administration, Washington, D.C., 1984.

14. Adams, D.S., Bowles, D.E., and Herakovich. C.T., Journal of Reinforced Plastics and Composites, Vol. 5, No. 3, July 1986, pp. 152-169. 
TABLE I. - FRACTURE MODES OF $[ \pm \theta]_{S}$ GRAPHITE-FIBER/EPOXY LAMINATES (DETERMINED BY SEM ANALYSIS)

[Longitudinal tension, LT; transverse tension, TT; intraply shear, S.]

\begin{tabular}{|c|c|c|c|}
\hline $\begin{array}{c}\text { Ply orien- } \\
\text { tation, } \\
\begin{array}{c} \pm \pm]_{\text {S }} \\
\text { deg }\end{array}\end{array}$ & $\begin{array}{c}\text { Solid } \\
\text { specimen }\end{array}$ & $\begin{array}{c}\text { Notched specimen } \\
\text { with slit }\end{array}$ & $\begin{array}{c}\text { Notch specimen } \\
\text { with hole }\end{array}$ \\
\hline 0 & LT & LT,S & LT,S \\
3 & LT,S & LT,S & LT,S \\
5 & LT,S & LT,S & LT,S \\
10 & LT,S & LT,S & LT,S \\
15 & LT,S & LT,S & LT,S \\
30 & LT,S & S, LT & S, LT \\
45 & S,LT & TT,S & TT,S \\
60 & TT,S & TT & TT \\
75 & TT & TT & TT \\
90 & TT & &
\end{tabular}

TABLE II. - SUMMARY OF THERMAL CYCLES PREDICTION FOR LAMINATES $\left[0_{2} / 90_{2}\right]_{S}$ AND $\left[0_{3} / 90\right]_{S}$ AT THREE CYCLIC TEMPERATURES (T300 GRAPHITE-FIBER/EPOXY MATRIX)

[Cure temperature assumed at $350{ }^{\circ} \mathrm{F}$; glass transition temperature, 420 ० $\mathrm{F}$; dry conditions, $M=0$ percent; assumed value for $B$ a 0.10.$]$

\begin{tabular}{|c|c|c|c|}
\hline \multirow[t]{2}{*}{ Condition or property } & \multicolumn{3}{|c|}{$\begin{array}{c}\text { Cyclic temperature, } \\
\Delta \mathrm{T},{ }^{\circ} \mathrm{F}\end{array}$} \\
\hline & -280 & -100 & -600 \\
\hline 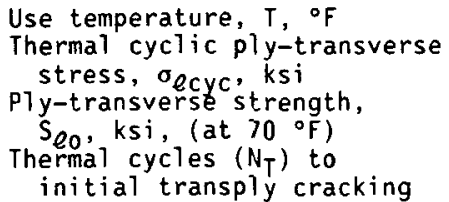 & $\begin{array}{r}70 \\
4.7 \\
\\
8 \\
10902\end{array}$ & $\begin{array}{r}250 \\
1.8 \\
6 \\
62 \quad 399\end{array}$ & $\begin{array}{r}-250 \\
\text { (a) } \\
11 \\
\text { (b) }\end{array}$ \\
\hline
\end{tabular}

${ }^{2}$ For laminate $\left[00_{2} / 90_{2}\right]_{\mathrm{s}}, 9.3 \mathrm{ksi}$; for laminate

$\left[0_{3} / 90\right]_{2}, 9.5 \mathrm{ksi}$.

${ }^{b}$ For 1 aminate $\left[0_{2} / 90_{2}\right]_{s}, 162$; for laminate $\left[0_{3} / 90\right]_{s}$, 91.

TABLE III. - NUMBER OF THERMAL CYCLES TO INITIAL TRANSPLY CRACKING IS VERY SENSITIVE TO TEMPERATURE PROFILE THROUGH-THE-LAMINATE THICKNESS $\left(\left[0_{2} / 90_{2}\right]_{S}{ }^{\prime}\right)$ T300 GRAPHITE-FIBER/EPOXY (LAMINATE)

[Cure temperature, $350^{\circ} \mathrm{F} ; \mathrm{gl}$ ass transition temperature, $420{ }^{\circ} \mathrm{F}$; thermal cyclic degradation coefficient, 0.1 ; room temperature dry ply-transverse tensile strength, $8 \mathrm{ksi}$.]

\begin{tabular}{|c|c|c|c|c|c|}
\hline \multirow{2}{*}{$\begin{array}{l}\text { Ply orien- } \\
\text { tation, } \\
\text { deg }\end{array}$} & \multicolumn{2}{|c|}{$\underset{\text { of }}{\text { Temperature, }} \Delta \mathrm{T}$, } & \multirow{2}{*}{$\begin{array}{l}\text { Use } \\
\text { temper- } \\
\text { ature, } \\
\text { of }\end{array}$} & \multirow{2}{*}{$\begin{array}{c}\text { Ply residual } \\
\text { stress, } \\
\sigma_{\ell 22} \\
\text { psi }\end{array}$} & \multirow{2}{*}{$\begin{array}{c}\text { Thermal } \\
\text { cycles } \\
\mathrm{N}_{T}\end{array}$} \\
\hline & Elevated & Cryogenic & & & \\
\hline 0 & $\begin{array}{l}-100 \\
-125 \\
-- \\
---\end{array}$ & $\begin{array}{l}-- \\
-600 \\
-575\end{array}$ & $\begin{array}{r}250 \\
225 \\
-250 \\
-225\end{array}$ & $\begin{array}{l}1771 \\
2250 \\
9347 \\
8924\end{array}$ & $\begin{array}{rr}52 & 399 \\
51 & 785 \\
& 29 \\
& 282\end{array}$ \\
\hline 90 & $\begin{array}{r}150 \\
175 \\
--- \\
--\end{array}$ & $\begin{array}{l}--- \\
--- \\
-550 \\
-525\end{array}$ & $\begin{array}{r}200 \\
175 \\
-200 \\
-175\end{array}$ & $\begin{array}{l}2695 \\
3174 \\
8544 \\
8121\end{array}$ & $\begin{array}{ll}35 & 748 \\
23 & 259 \\
& 484 \\
& 819\end{array}$ \\
\hline
\end{tabular}


TABLE IV. - CYCLES TO INITIATE TRANSPLY CRACKS DEPEND ON LAMINATE CONFIGURATION AND TYPE OF LOADING CONDITIONS (AS GRAPHITE-FIBER/EPOXY AT 0.62 FVR)

[Fatigue degradation coefficients are assumed to be $B_{M}=B_{T}=B_{L}=0.1$.]

(a) Ply-transverse stress influence coefficients

\begin{tabular}{|c|c|c|c|}
\hline \multirow[t]{2}{*}{ Loading condition } & \multicolumn{3}{|c|}{ Laminate configuration } \\
\hline & {$[ \pm 45 / 0 / 90]_{S}$} & {$\left[90_{2} / \pm 10\right]_{5}$} & {$\left[ \pm 30 / 0_{3}\right]_{s}$} \\
\hline 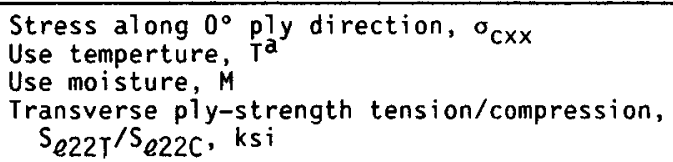 & $\begin{array}{r}0.145 \\
-16.681 \\
-1298.265 \\
8 / 20\end{array}$ & $\begin{array}{r}0.170 \\
-12.280 \\
-1170.719 \\
8 / 20\end{array}$ & $\begin{array}{r}-0.022 \\
-7.698 \\
-571.146 \\
8 / 20\end{array}$ \\
\hline
\end{tabular}

(b) Cycles to failure

\begin{tabular}{|c|c|c|c|c|}
\hline \multirow[t]{2}{*}{ Loading condition } & \multicolumn{3}{|c|}{ Laminate configuration } & \multirow[t]{2}{*}{ Comments } \\
\hline & {$[ \pm 45 / 0 / 90]_{s}$} & {$\left[90_{2} / \pm 10\right]_{s}$} & {$\left[ \pm 30 / 0_{3}\right]_{s}$} & \\
\hline Applied stress, $N_{L}$ & 36500 & 4220 & $>100 \times 10^{6}$ & $\sigma_{c x x} \square 30 \mathrm{ksi}$ \\
\hline Applied stress and residual stress, $N_{L}$ & 1 & 1 & $>100 \times 10^{6}$ & $\sigma_{c x x}=30 \mathrm{ksi}+\sigma_{R}$ \\
\hline Elevated temperature cycling ${ }^{b}, N_{T}$ & 76620 & 234060 & 987000 & $T=250^{\circ} \mathrm{F}$ \\
\hline Cryogenic temperature cycling ${ }^{b}, N_{T}$ & 180 & 275260 & $>100 \times 10^{6}$ & $T=300^{\circ} \mathrm{F}$ \\
\hline Moisture cycling $c, N_{M}$ & $>100 \times 10^{6}$ & $>100 \times 10^{6}$ & $>100 \times 10^{6}$ & $M \square 1$ percent \\
\hline
\end{tabular}

aCure temperature, $350^{\circ} \mathrm{F}$.

${ }^{b} \mathrm{Cyclic}$ temperatures are from room temperature to $T$.

${ }^{C}$ Cyclic moisture is from dry to $M$.

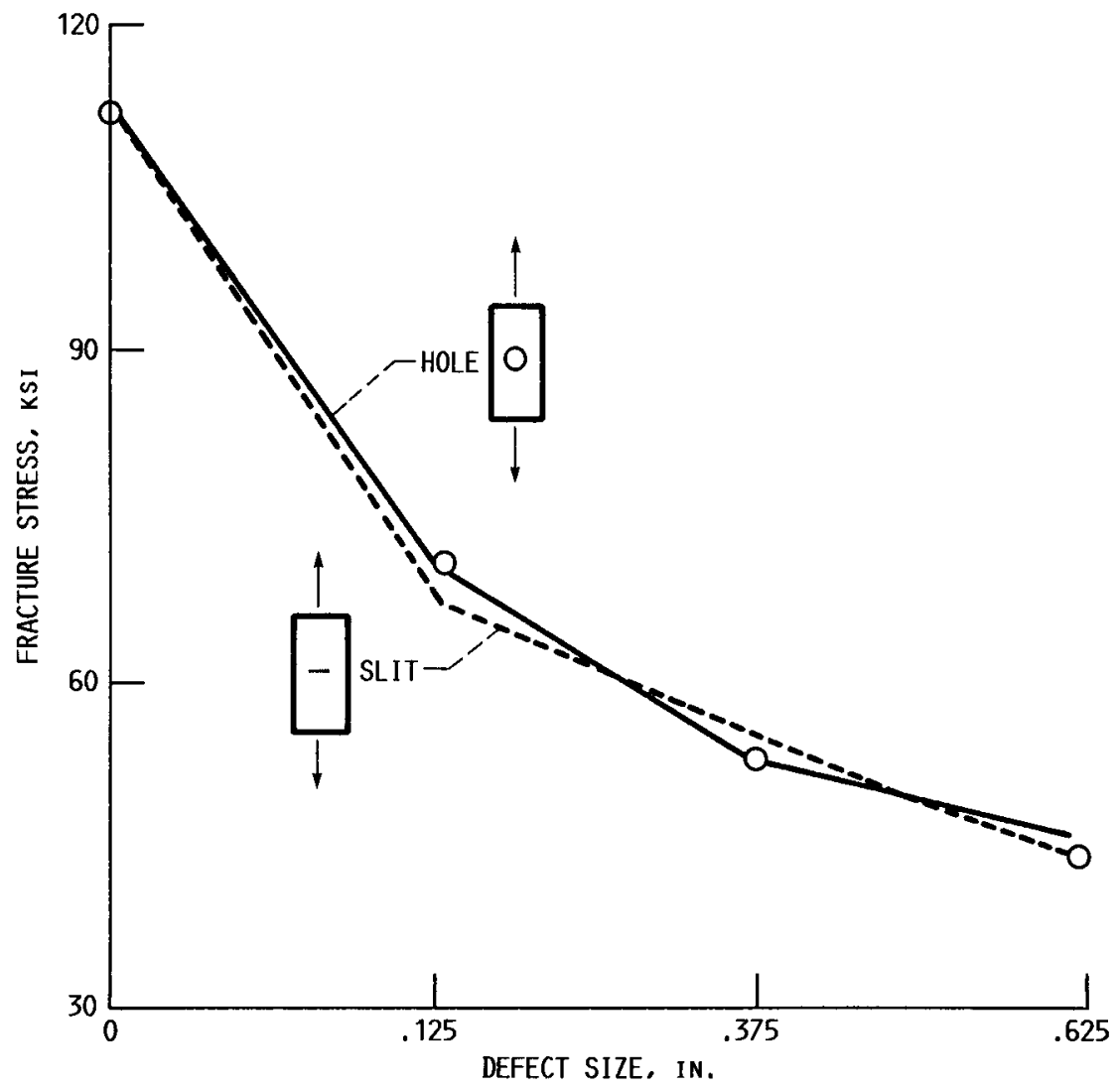

Figure 1. - Laminate Static Fracture Data, $\left([0 / \pm 45 / 90]_{2 S}\right.$. T300/E). 


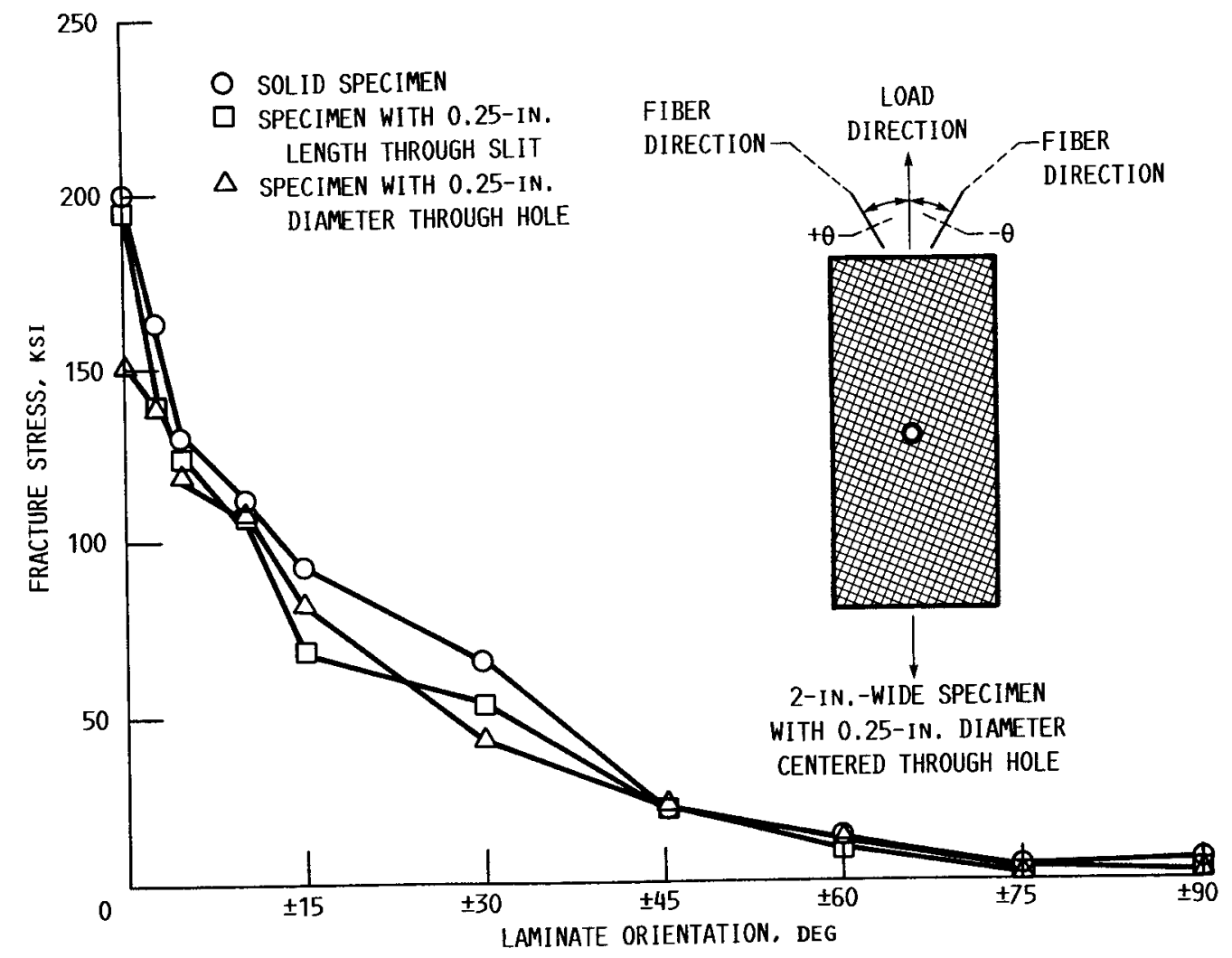

FIGURE 2. - ANGLEPLIED LAMINATE LONGITUDINAL STRENGTHS.

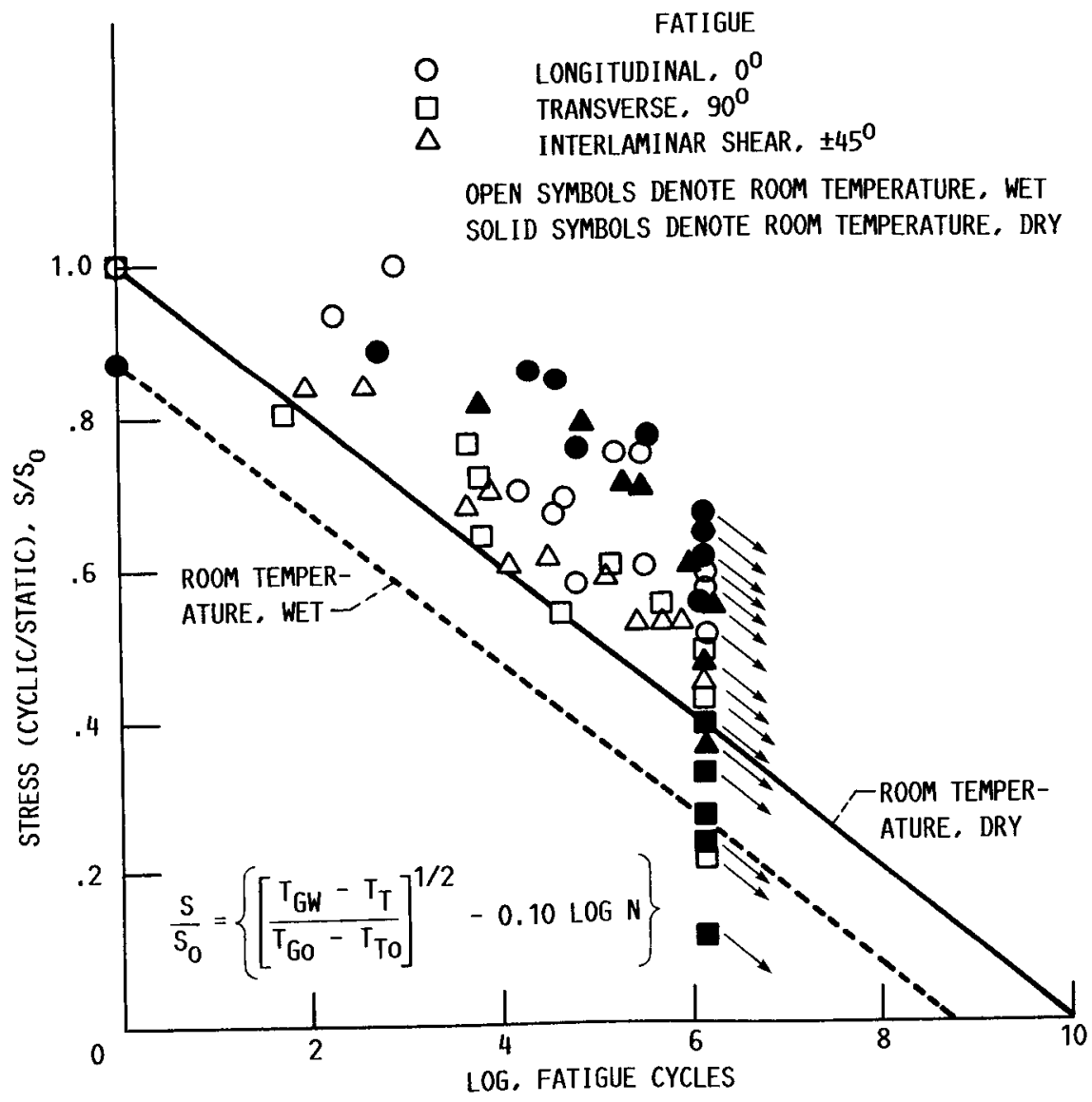

FIGURE 3. - COMPRESSIVE LIFE AND DURABILITY AS GRAPHITE-FIBER/EPOXY. 


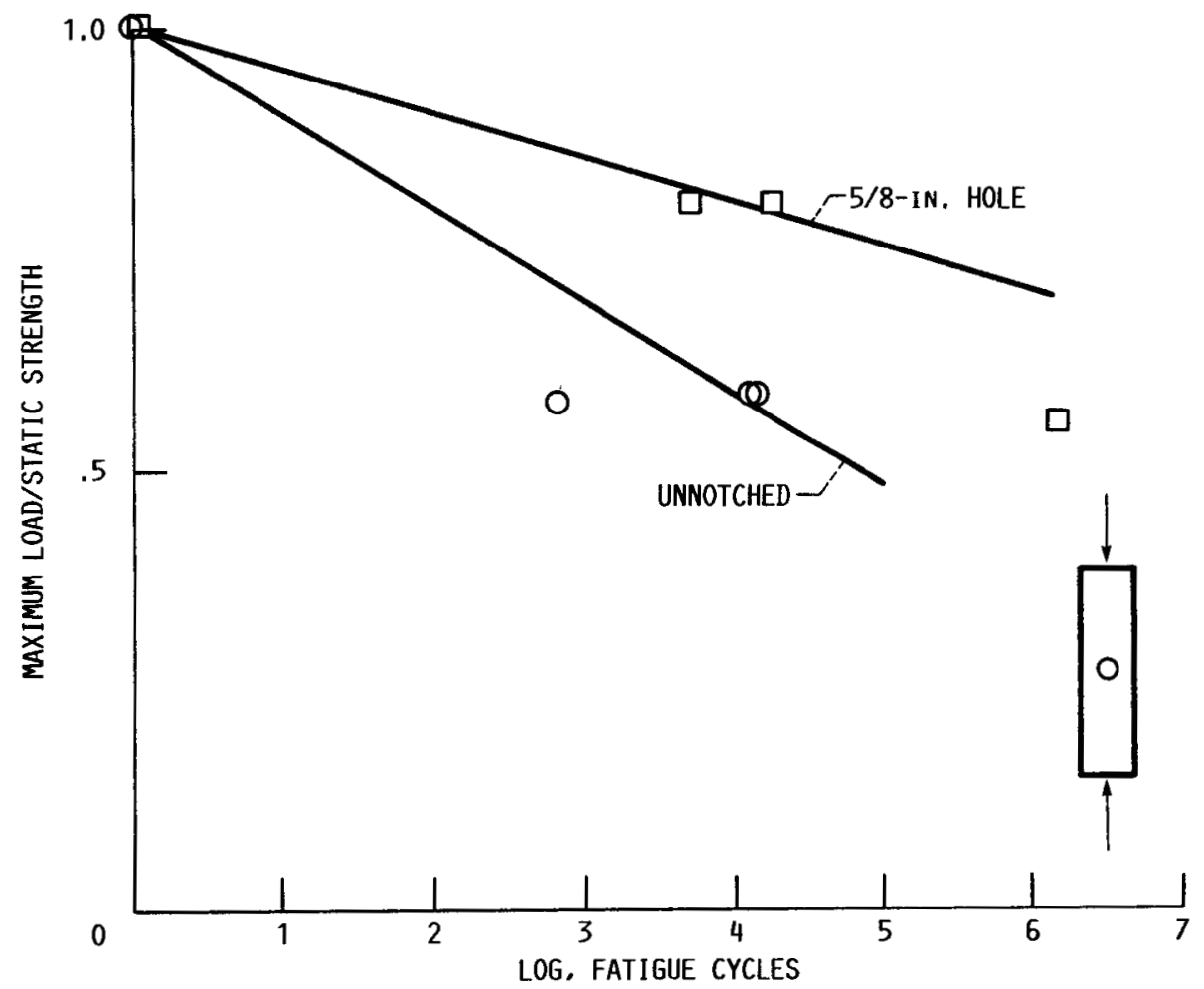

FIGURE 4. - NOTCH LAMINATES ARE NOT SENSITIVE TO COMPRESSION FATIGUE (FOR $[0 / \pm 45 / 0 / 90]_{2 S}, T 300 / 934$ ). 


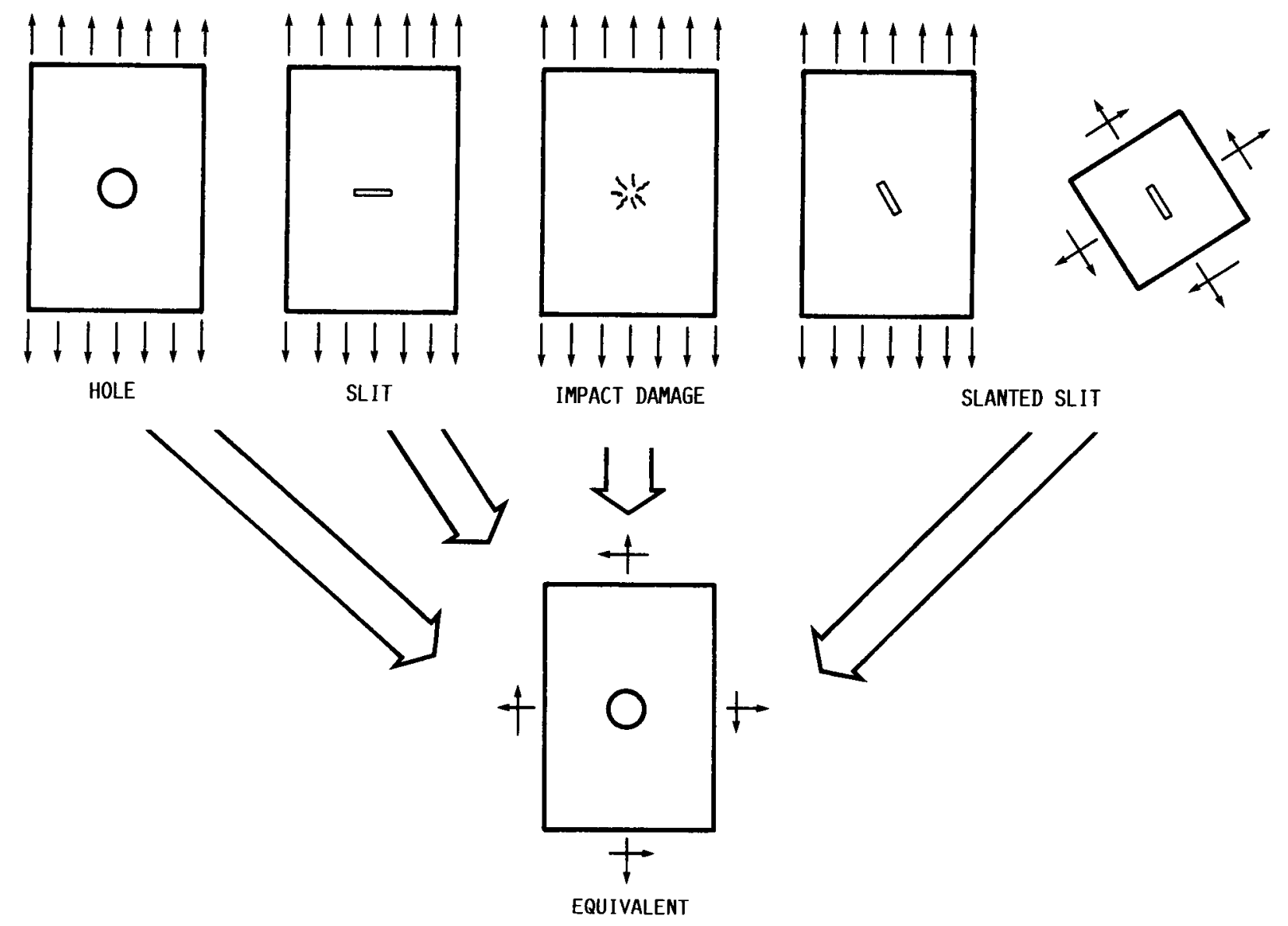

FIGURE 5. - SIMULATION OF DEFECTS IN LAMINATES FOR APPROXIMATE ANALYSIS. 

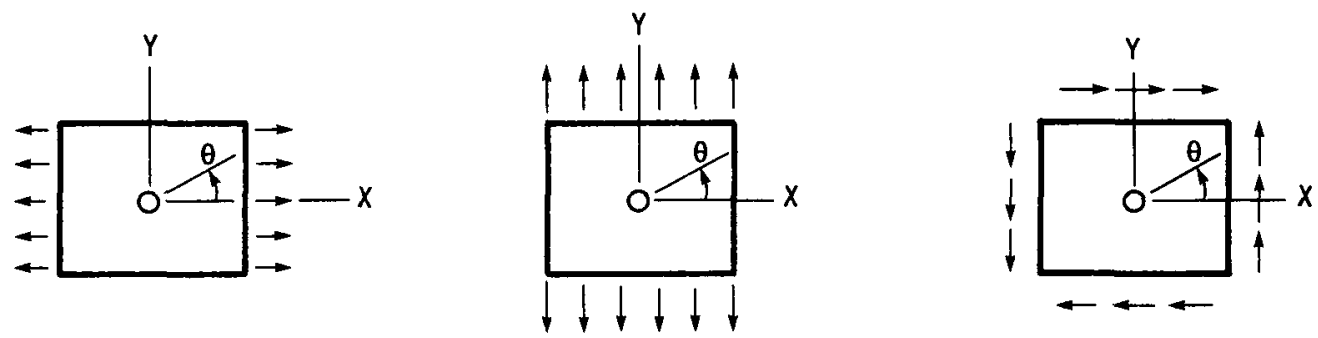

$K_{T}^{(x)}=\frac{\sigma_{C \theta \theta}}{\sigma_{C X x}}=\frac{E_{c \theta \theta}}{E_{C X x}}$

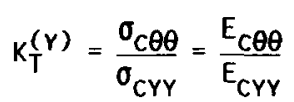

$K_{T}^{(X Y)}=\frac{\sigma_{C \theta \theta}}{\sigma_{C X Y}}=\frac{E_{C \theta \theta}}{2 E_{C X X}}$

$x\left[-R_{0} \cos ^{2} \theta\right.$

$x\left[-R_{0} \sin ^{2} \theta\right.$

$x\left[-R_{D I}\left(1+R_{0}+R_{D I}\right)\right]$

$\left.+\left(1+R_{D I}\right) \sin ^{2} \theta\right]$

$\left.+\left(1+R_{D I}\right) \cos ^{2} \theta\right]$

$x \sin 2 \theta$

WHERE $R_{0}=\left[E_{C X X} / E_{C Y Y}\right]^{1 / 2}$ AND $R_{D I}=\left[2\left(\frac{E_{C X X}}{E_{C Y Y}}-v_{C X Y}\right)+\frac{E_{C X X}}{G_{C X Y}}\right]^{1 / 2}$

FIGURE 6. - SUPERPOSITION OF RESPECTIVE STRESS CONCENTRATION FACTORS. DEFECT SIMULATED BY CIRCILLAR HOLE WITH DIAMETER EQUAL TO DEFECT SIZE. LINEAR BEHAVIOR TO FIRST PLY OR INTERPLY DAMAGE. NOTE: $\sigma_{\mathrm{C} \theta \theta}$ IS THE HOOP STRESS AT $\theta$. 


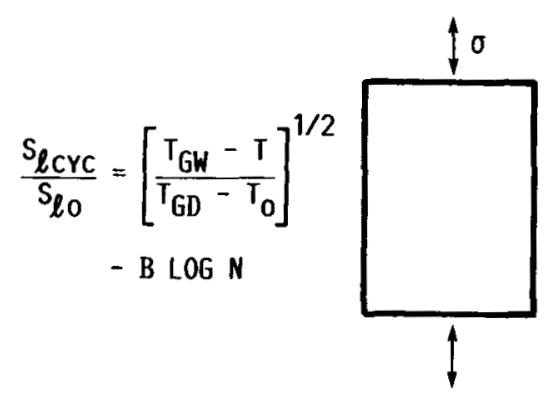

(A) LAMINATE WITHOUT DEFECTS.

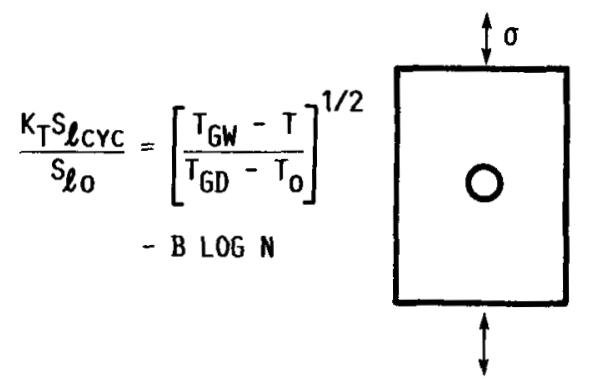

(B) LAMINATE WITH DEFECTS.

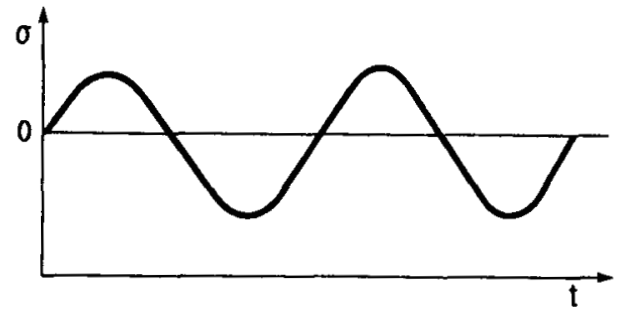

(C) CYCLIC LOAD, CONSTANT STRESS AMPLITUDE.

FIGURE 7, - FATIGUE AND FRACTURE FOR MECHANICAL LOAD ONLY. CRITERIA FOR FIRST PLY FAILURE ARE (1) TRANSPLY CRACKING AND (2) DELAMINATION. 

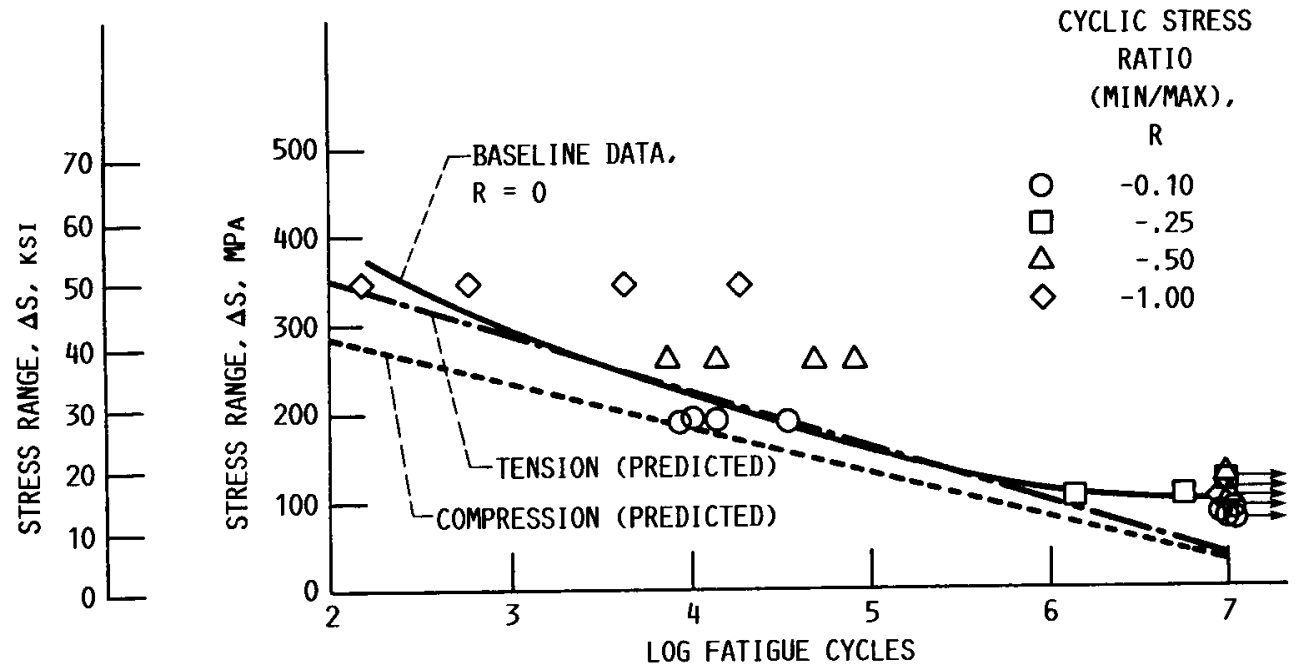

FIGURE 8. - COMPARISON OF EFFECT OF MEAN STRESS ON FATIGUE ENDURANCE. (TESTS CONDUCTED AT $70^{\circ} \mathrm{F}$ AND 50 PERCENT RH.)

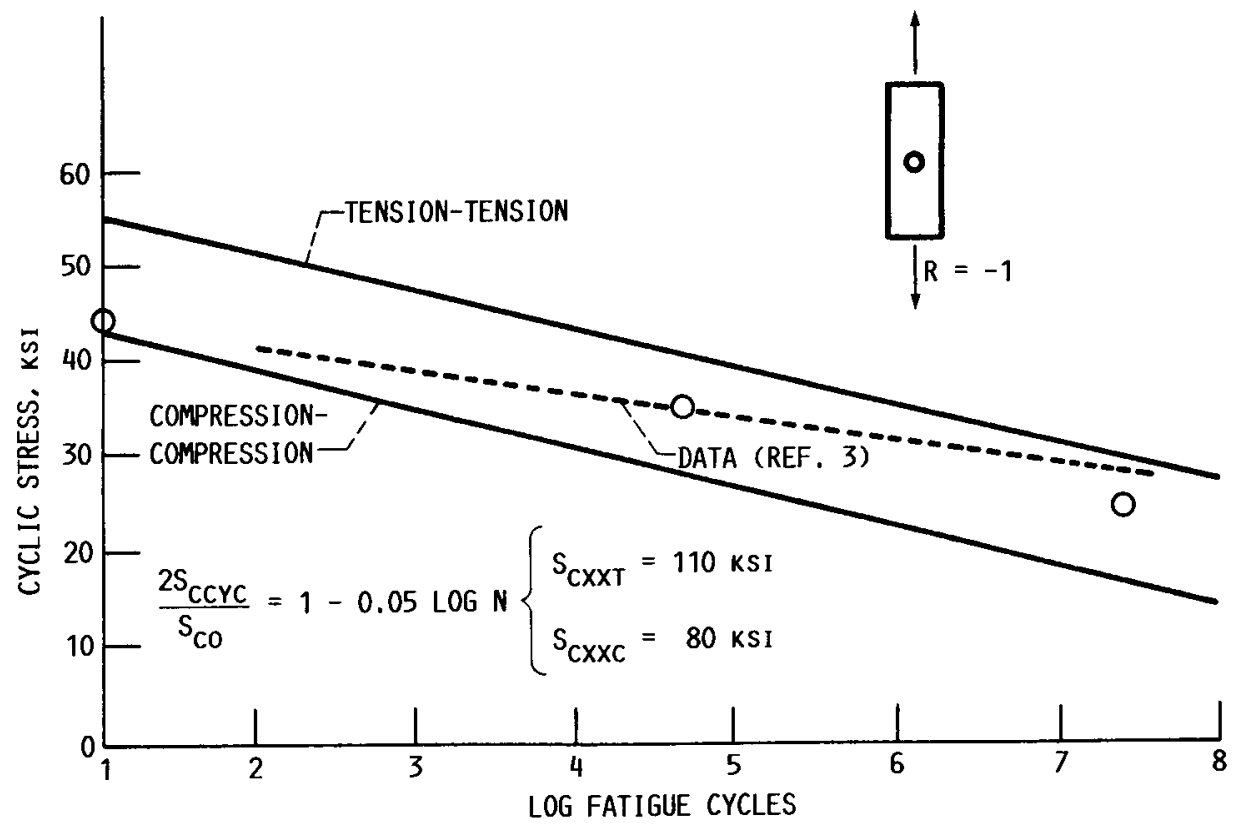

FIGURE 9. - COMPARISONS OF PREDICTED FATIGUE STRENGTH WITH DATA ([0/ $\pm 45 / 0 / 90]_{2 S}$ T300/E LAMINATE). 
(1) CRITERIA

INITIAL DAMAGE WITH NO PENETRATION

INITIAL DAMAGE WITH INTERLAMINAR DELAMINATION

(2) EQUIVALENCE

RIGID PROJECTILE SPHERE (D)

DAMAGED AREA BOUNDARIES ARE

$0.5 \times$ PROJECTILE-PROJECTED AREA

ENERGY BALANCE

$\frac{1}{2} \frac{\pi}{6} D^{3} \frac{P}{g} V^{2}=\frac{1}{4} \frac{\pi}{4} D^{2} S_{\ell 13}{ }^{t} C$

IMPACTING VELOCITY TO INITIAL DAMAGE

$$
V=\left[0.75\left(\frac{g}{\rho}\right)\left(\frac{{ }^{t} C}{D}\right) s_{l 13}\right]^{1 / 2}
$$

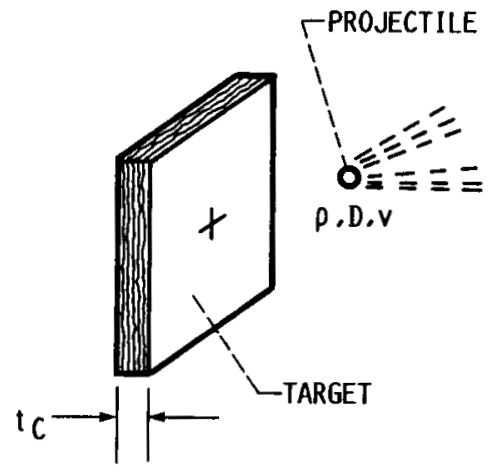

HEIGHT-DROP EQUIVALENT

$$
H=\left[1.5\left(\frac{{ }^{t} C}{D}\right) \frac{S_{l 13}}{\rho}\right]
$$

FIGURE 10. - IMPACT RESISTANCE FOR LOCAL LAMINATE CHARACTERISTIC.

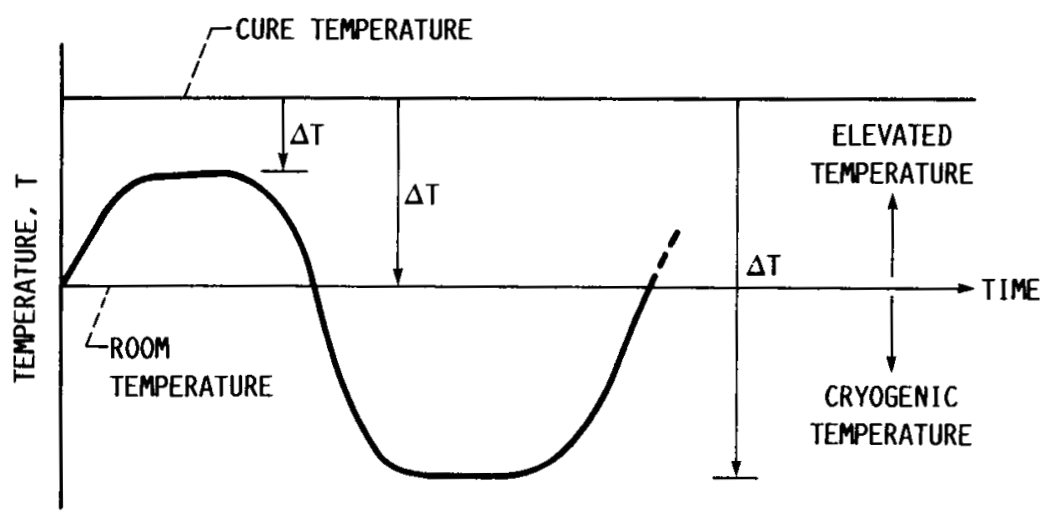

THERMAL CYCLES

$$
\begin{aligned}
\text { LOG } N_{T}= & \frac{1}{B}\left[\left(\frac{T_{G W}-T}{T_{G D}-T_{0}}\right)^{1 / 2}-\frac{\sigma_{\ell Y Y C Y C}}{S_{\ell Y Y O}}\right] \\
\sigma_{\ell 22 C Y C}= & \text { MAXIMUM TRANSVERSE PLY STRESS AT } \Delta T \text { TO YIELD } \\
& \text { MAXIMUM }\left(\sigma_{\ell Y Y C Y C} / S_{\ell Y Y O}\right) \text { RATIO }
\end{aligned}
$$

FIGURE 11. - THERMAL FATIGUE AND CYCLES TO INITIAL CRACKING (FIRST PLY INITIAL TRANSVERSE (RACKING). 


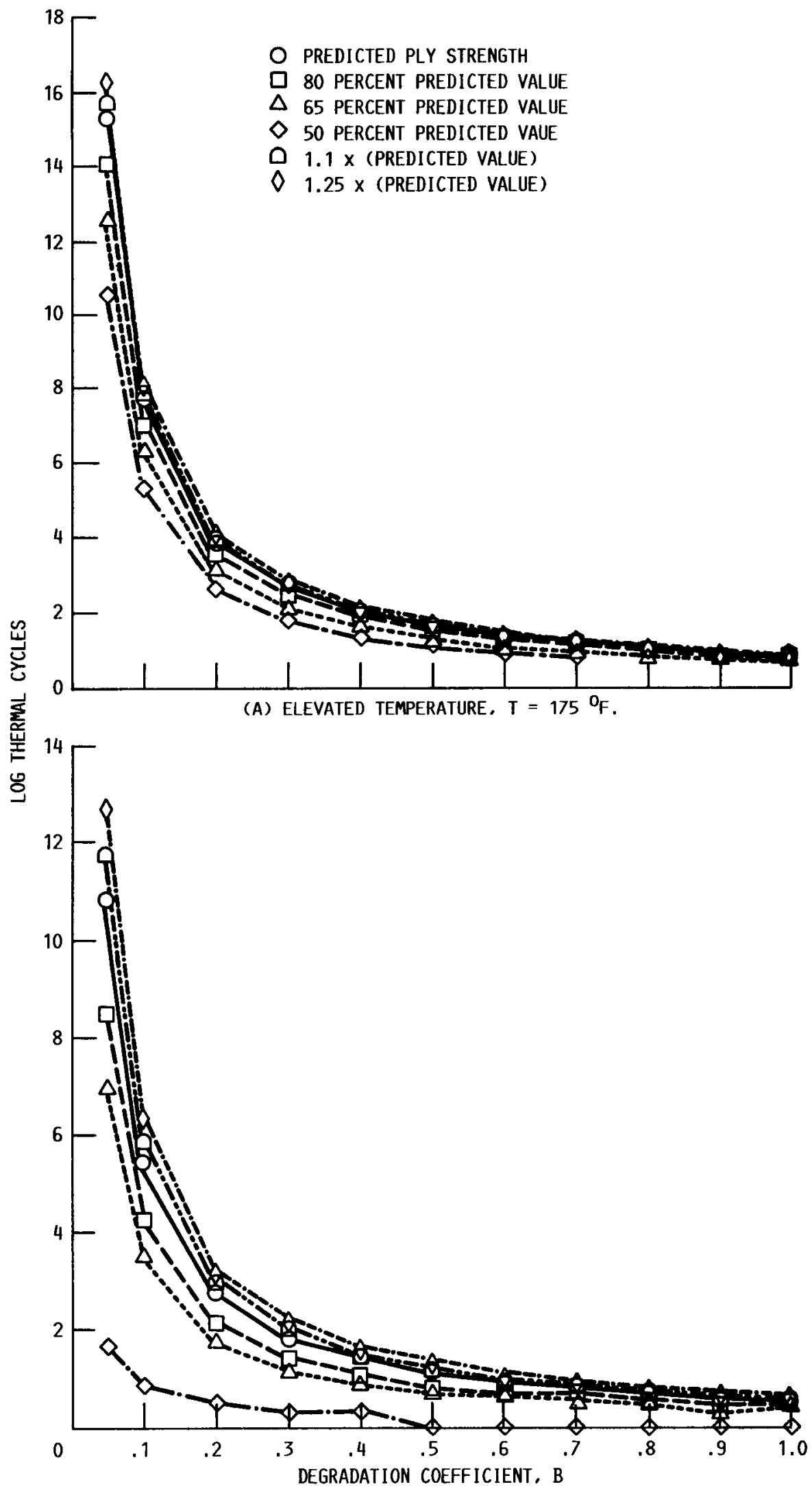

(B) CRYOGenIC TEMPERATURE, $T=-250^{\circ} \mathrm{F}$.

FIGURE 12. - THERMAL CYCLES TO FAILURE. SENSITIVITY TO DEGRADATION COEFFICIENT B AND TO IN SITU PLY STRENGTH $\left[0 / 90_{3}\right]_{S}$ T300 GRAPHITE FIBER/ EPOXY LAMINATE. 

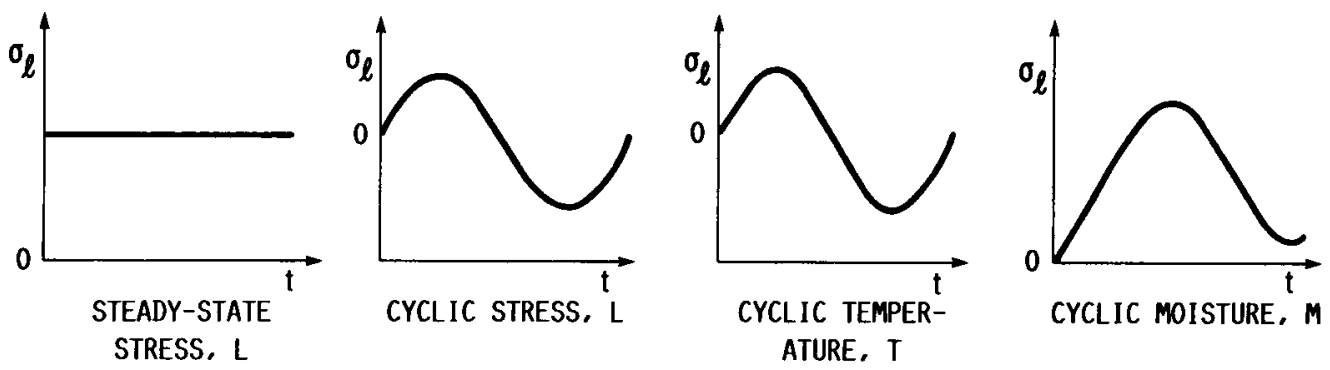

$$
\left(\frac{\sigma_{\ell}}{s_{\ell}}\right)_{L}+\left(\frac{\sigma_{\ell C Y C}}{s_{\ell C Y C}}\right)_{L}+\left(\frac{\sigma_{\ell C Y C}}{s_{\ell C Y C}}\right)_{T}+\left(\frac{\sigma_{\ell C Y C}}{s_{\ell C Y C}}\right)_{M}<1 / K_{T} \text { (FOR EACH PLY STRESS) }
$$

$\frac{s_{\ell}}{s_{\ell_{0}}}=F_{H T} ：\left(\frac{s_{\ell C Y C}}{s_{\ell_{0}}}\right)_{L}=F_{H T}-B_{L} \operatorname{LOG~N}: \quad\left(\frac{s_{\ell C Y C}}{s_{\ell_{0}}}\right)_{T}=F_{H T}-B_{T}$ LOG N $;$

$$
\left(\frac{S_{\ell C Y C}}{S_{\ell 0}}\right)_{M}=F_{H T}-B_{M} \text { LOG NM }: \quad F_{H T}=\left[\frac{T_{G W}-T}{T_{G D}-T_{0}}\right]^{1 / 2}
$$

FIGURE 13. - COMBINED HYGROTHERMOMECHANICAL CYCLIC LOADINGS. $\quad\left(K_{T}=\right.$ STRESS CONCENTRATION FACTOR.) 


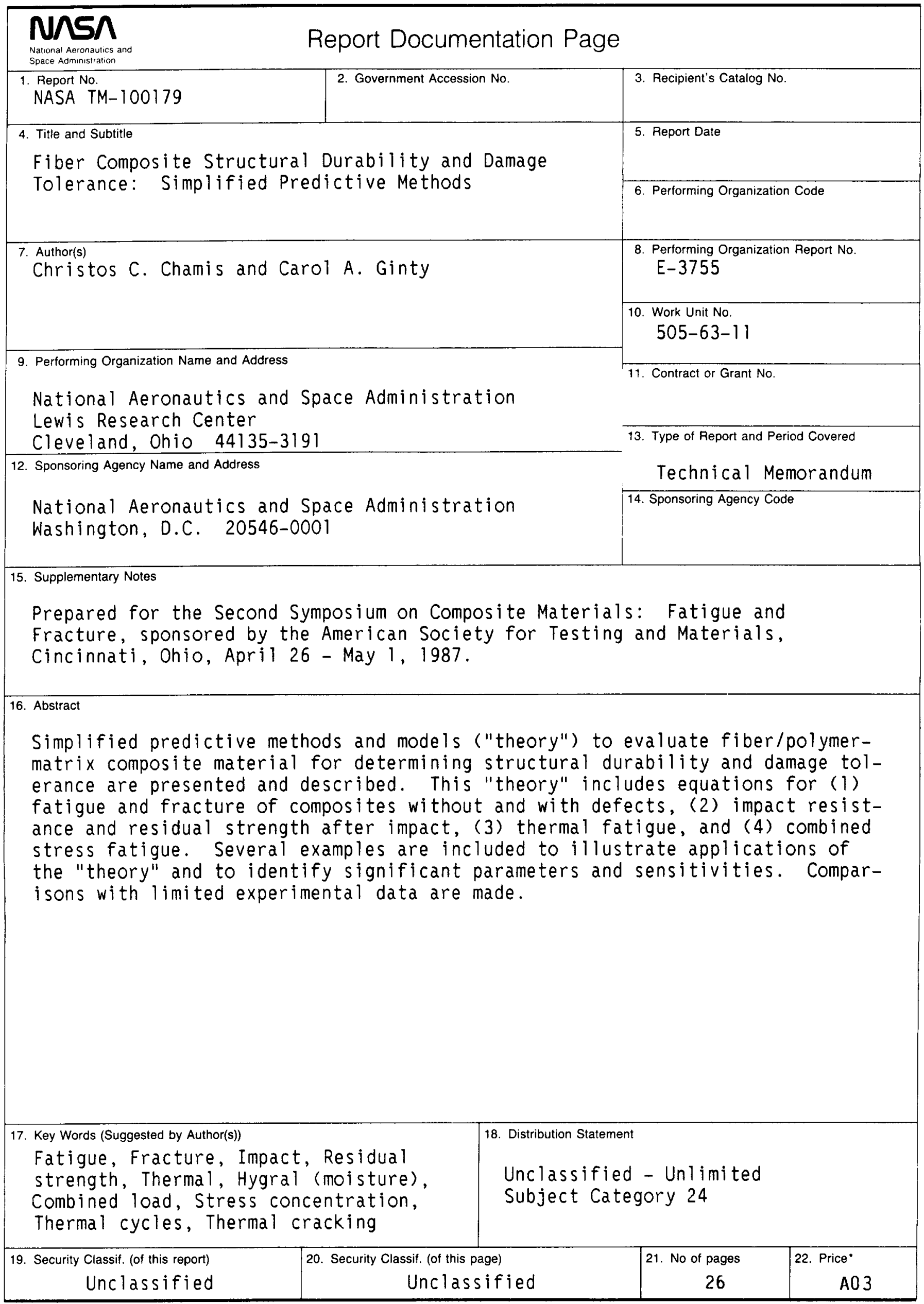

